\title{
Wacana Islamofobia Dalam Media Malaysia: Obligasi, Isu-isu dan Cabaran
}

Lee Kuok Tiung, Aisah Meri (Universiti Malaysia Sabah)

Siti Suriani Othman (Universiti Tuanku Abdul Rahman) \&

Liana Bt. Mat Nayan (Universiti Sains Islam Malaysia)

\begin{abstract}
Abstrak
Kajian ini bertujuan menganalisis komitmen dan usaha yang dilakukan oleh media di Malaysia untuk membendung penularan propaganda dan sentimen yang bermotif mengaibkan nama baik Islam dan Muslim di samping usaha-usaha meneutralkan sterotaip rasis tersebut dengan memberikan maklumat yang tepat berkenaan Islam dan Muslim. Hasil dapatan kajian melalui kaedah temubual mendalam dengan pengamal media dari beberapa buah akhbar arus perdana, stesen radio dan televisyen FTA terpilih telah merumuskan dasar dan polisi kerajaan Malaysia pada dasarnya secara tidak langsung sudah menyumbang kepada usaha-usaha mengawal penularan gejala Islamofobia. Komitmen untuk menjelas, mendidik dan memberikan kefahaman yang tepat tentang ajaran Islam dan Muslim sering mendapat tempat menerusi rancangan-rancangan yang diterbitkan terutama melalui saluran media kerajaan. Tidak dinafikan ada berlaku insiden-insiden yang secara mudahnya boleh dimanipulasi untuk mencetuskan persengketaan sesama rakyat Malaysia yang berbilang etnik dan agama, tetapi media di Malaysia sentiasa komited membantu mengawal dan meredakan keadaan. Kebanyakan usaha ini lahir daripada kesedaran tanggungjawab diri pengamal media di Malaysia untuk mengekalkan suasana aman dan harmoni dalam kalangan masyarakat pluralistik Malaysia.
\end{abstract}

Kata Kunci: islamofobia, pembingkaian, ekonomi politik, rasis, \& masyarakat pluralistik

\section{Pengenalan}

Penularan Islamofobia (Islamophobia) yang membawa nilai benci, stereotaip negatif dan prejudis terhadap Islam dan Muslim menerusi kandungan media Barat telah membimbangkan pelbagai lapisan masyarakat Malaysia. Antara penerbitan yang menimbulkan kontorversi ialah "Innocence of Muslims" yang telah membangkitkan kemarahan masyarakat Islam terhadap golongan yang dilihat sentiasa memprovokasi masyarakat Islam. Islam dan Muslim seolah-olah menjadi sasaran penerbit kandungan media di Barat. Berdasarkan penemuan kajian-kajian berkenaan Islamofobia, sebahagian besar negara-negara di dunia begitu obses dengan kandungan media yang mengadvokasi Islamofobia daripada pihak Barat. Pola yang mulai ketara boleh dilihat dalam industri perfileman masa kini adalah watak-watak jahat dalam filem-filem Hollywood telah bertukar daripada komunisme kepada terorisme terutama semenjak peristiwa 11 September 2001.

Malaysia merupakan sebuah negara sekular yang mempunyai keunikannya yang tersendiri kerana Islam merupakan agama rasmi Persekutuan sepertimana termaktub dalam Perkara 3(1) yang berbunyi "Islam ialah agama bagi Persekutuan; tetapi agama-agama lain boleh diamalkan dengan aman dan damai di mana-mana Bahagian Persekutuan". Rakyatnya terdiri daripada masyarakat majmuk yang berbilang etnik dan mengamalkan kepercayaan agama dan kebudayaan yang berbeza diambilkira dalam pertimbangan penerbitan media. Agenda perpaduan kaum sentiasa mendapat perhatian kerajaan dan media di Malaysia. Peristiwa 13 Mei 1969 sering dijadikan rujukan untuk mengingatkan rakyat implikasi negatif perseteruan kaum. Namun, globalisasi yang menyaksikan ketembusan saluran-saluran media asing ke dalam mediaskap Malaysia telah mewujudkan cabaran baharu kepada pengusaha kandungan media nasional untuk menepis pengaliran masuk unsur-unsur negatif menerusi 
kandungan media. Ini juga bermakna pengusaha media dalam negara berdepan dengan pesaing daripada dalam dan luar negara.

Dalam hal ini, ketembusan Islamofobia ke dalam kalangan rakyat Malaysia boleh dilihat sebagai rentetan daripada mediaskap di Malaysia sendiri yang 'kaya media'. Misalnya, antara 1963 hingga 1984 hanya terdapat dua saluran televisyen sahaja iaitu TV1 dan TV2 di Malaysia. Monopoli tersebut mulai dipecahkan apabila berlaku perubahan dasar kerajaan membenarkan pihak swasta tampil membekalkan stesen televisyen sebagai pilihan tambahan atau alternatif kepada rakyat Malaysia. Kesannya, pada hari ini terdapat lebih kurang 80 akhbar harian dan mingguan, lebih 50 saluran radio sama ada kerajaan mahupun swasta, enam saluran televisyen terestarial iaitu FTA (free-to-air) yang boleh ditonton secara percuma dibawa oleh Jabatan Penyiaran melalui Radio dan Televisyen Malaysia (RTM) dan Media Prima Berhad, 110 saluran televisyen berbayar oleh All Asia Network (ASTRO) menerusi satelit dan terkini adalah 79 saluran IPTV oleh TELEKOM Malaysia (TM televisyen - 39 saluran) dan FINE TV (40 saluran) melalui jalur lebar (broadband), dan ini tidak termasuk pilihan yang boleh diakses melalui TVRO yang mencecah ribuan saluran dari seluruh dunia.

Situasi ini meletakkan Malaysia dalam dunia tanpa sempadan atau 'perkampungan global' (global village) (McLuhan, 1964) dengan saluran-saluran media antarabangsa tersebut bertindak sebagai agen pembawa. Sekaligus, senario ini memaksa media di Malaysia mempertingkatkan usaha-usaha untuk menangkis dan seterusnya berusaha membentuk persepsi yang positif dalam kalangan rakyat Malaysia terhadap Islam dan Muslim, seterusnya mengurangkan unsur Islamofobia dalam kalangan khalayak media.

\section{Objektif}

Prejudis terhadap Muslim dan Islam telah menimbulkan minat dan sikap ingin tahu dalam kalangan sarjana dan penyelidik untuk mengkaji permasalahan ini. Objektif pertama kajian ini adalah mengenalpasti persepsi pengamal media di media nasional Malaysia terhadap penularan fenomena Islamofobia menerusi media. Ini terutama sikap media di Malaysia terhadap Islam dan Muslim dalam usaha memahami orientasi media di Malaysia terhadap bias agama dan perkauman di Malaysia. Objektif kedua kajian ini adalah mengenalpasti usahausaha yang dilakukan oleh media di Malaysia untuk menangani prejudis media global terhadap Islamofobia dan Muslim. Ini merangkumi usaha-usaha pembingkaian seperti meneutralkan pemaparan-pemaparan laporan negatif seperti Jihad yang disalah konsepkan oleh Fox News yang menjadi mouthpieces pelbagai pihak masa kini.

\section{Kaedah Kajian}

Diskusi kajian ini diperolehi daripada temubual mendalam (in-depth interview) dengan pekerja-pekerja media (media workers) dari pelbagai pengkhususan iaitu wartawan, editor dan juga wakil daripada pengurusan organisasi media yang merangkumi akhbar dan stesen televisyen. Antara syarat pemilihan (screening) sampel adalah informan mestilah bertugas minimum lima tahun dalam organisasi media tersebut dan merupakan wartawan kanan (BJ kalau penyiaran) dan editor dalam organisasi media berkenaan. Mengambilkira good representative atau perwakilan terbaik, informan-informan kajian ini diperolehi dari organisasi media kewartawanan dan penyiaran iaitu bilik berita stesen televisyen di bawah Media Prima, Bilik Berita Hal Ehwal Semasa (BES), RTM, dan dua akhbar arus perdana nasional dan dua akhbar tempatan di Sabah. 


\section{Dapatan Kajian Dan Perbincangan}

Keseluruhannya perbincangan dapatan kajian ini berdasarkan temubual mendalam dengan pengamal media daripada media penyiaran sama ada televisyen atau radio, dan akhbar versi cetak. Perbincangan tentang tahap penularan Islamofobia di sesebuah negara amat bergantung kepada persekitaran dan set-up negara yang dibincangkan dan mengambilkira kewujudan pelbagai bahasa, sejarah, tahap pembangunan ekonomi dan amalan kebudayaan yang berbezabeza.

\section{Faktor-Faktor Penularanan Islamofobia}

Reaksi pengamal media Malaysia terhadap Islamofobia menunjukkan rata-rata mereka peka dengan peningkatan agenda media Barat untuk memburuk-burukkan nama baik Islam dan Muslim. Umumnya menurut informan kebanjiran saluran media asing hasil kemajuan teknologi komunikasi dalam mediaskap Malaysia dipercayai menyumbang kepada penularan Islamofobia dalam kalangan masyarakat Malaysia. Menurut informan, "jumlah liputan yang tidak seimbang" disebabkan jumlah saluran-saluran media asing dari Barat yang mendukung sentimen anti-Islam dan anti-Muslim sedikit-sebanyak telah meresap ke dalam pemikiran rakyat Malaysia. Sentimen Islamofobia menerusi kandungan media Barat secara tidak langsung mempengaruhi pemikiran rakyat Malaysia yang meminati saluran-saluran asing. Propaganda-propaganda berniat jahat yang terselit dalam kandungan media Barat untuk memesongkan pemikiran dan persepsi penduduk dunia terhadap Islam kini terlalu banyak berbanding pihak yang bertekad memperbetulkan fakta dan memberitahu Islam dan Muslim yang sebenar.

Dalam masa sama, sukar untuk menolak kandungan media Barat yang menyelitkan propaganda yang menjurus kepada Islamofobia untuk menutup pekung dan sengkelat diri mereka. Ini berpunca daripada ideologi dan kepentingan diri yang berbeza tidak kira sama ada dalam konteks politik, ekonomi mahupun nasional. Informan telah memberi pelbagai contoh seperti penaklukan Amerika Syarikat (AS) ke atas Iraq pada tahun 2003 dengan alasan Iraq memiliki senjata pembunuh massa (Weapon of Mass Destruction - WMD). Rata-rata penduduk dunia pada hari ini telah terlepas pandang tanggungjawab AS terhadap pertuduhan yang dilemparkan tersebut. Bekas presiden Iraq, Saddam Hussein yang merupakan satusatunya pemimpin Islam yang telah melancarkan peluru berpandu Scud ke Tel Aviv, Israel pada tahun 1991 iaitu sebelum Perang Teluk (Gulf War) telahpun dijatuhi hukuman mati oleh AS.

Keagresifan media di Barat mempromosikan Islamofobia juga dipercayai untuk mengalih perhatian rakyat dalam negara masing-masing terhadap masalah-masalah internal negara yang bersilih-ganti seperti yang dihadapi AS dan anggota-anggota EU khususnya PIGS iaitu Portugal, Itali, Greek dan Sepanyol kepada 'musuh luar' yang dicipta media. Agak malang di sini kerana Islam dan Muslim telah dijadikan sasaran mereka. Begitupun, menjawab sebab media Barat melancarkan Islamofobia, terdapat juga informan-informan yang berpendapat, "Jewish [people] does not only own the media but run the media," dan "Feel uneasy with others." Ini dikaitkan dengan pemilikan media dan semudah rasa iri hati dengan pihak lain. Terdapat juga pandangan yang lebih 'berat' sedikit sifatnya iaitu disebabkan "Religion ... is the easiest way ....to gain supports ... as communism has decreased, even China today is becoming more liberal and being liberalized, so easiest way is to use terrorism as the new agenda."

Apa-apapun terdapat juga 'faktor penarik' disebabkan kelemahan-kelemahan yang terdapat di sesetengah negara-negara Islam itu sendiri seperti diskriminasi terhadap kaum 
wanita dan pergerakan puak radikal yang mana sebenarnya bukan berasal daripada ajaran agama Islam itu sendiri. Perkara-perkara yang bercanggah dengan tuntutan hak asasi manusia ini membuka peluang kepada media di Barat mencemarkan nama baik Islam dan Muslim, tambahan lagi ada sesetengah individu itu sendiri yang mudah diperalatkan untuk memperkukuhkan dakwaan media Barat.

Faktor penyumbang dari dalam negara sendiri sepertimana memetik pendapat daripada informan, "pelaporan media berdasarkan pengetahuan yang cetek dan ideologi politik" turut menyumbang kepada penularan Islamofobia dalam kalangan rakyat Malaysia. Antara contoh yang diberikan oleh informan adalah isu pertikaian penggunaan kalimah Allah dalam Herald menyinggung perasaan penganut agama Kristian yang telah lama menggunakannya. Menurut informan, "seseorang wartawan yang ada membuat sedikit kajian, mereka harus menyedari perkataan "Allah" bermaksud "Tuhan" dalam Bahasa Arab dan ..... mana-mana pihak yang cuba menuntut hak eksklusif terhadap penggunaan istilah tersebut harus menyedari [mempertimbangkan] perkataan tersebut telah lama wujud sebelum ajaran Islam diperkenalkan." Begitu juga dengan pelaporan berita tentang perancangan PAS melaksanakan Hudud sekiranya PR berjaya membentuk kerajaan Malaysia dalam PRU ke-13 jelas telah menimbulkan ketakutan terhadap konsep Islam dan amalan Muslim yang diwarwarkan. Ini bukan sahaja dalam kalangan bukan Islam tetapi juga dalam kalangan Muslim sendiri.

Terdapat juga isu-isu peminggiran sosial di Malaysia yang berteraskan kecelaruan moral yang telah mencalarkan nama baik Islam dan Muslim seperti Seksualiti Merdeka. Pendirian devian yang melawan arus perdana tersebut dilihat mencalar nama baik Islam apabila ada Muslim sendiri yang terlibat sama. Begitu juga halnya dengan gerakan anasiranasir Jemaah Islamiah (JI) di Malaysia juga merupakan suatu isu hangat dan insiden rampasan senjata oleh anggota kumpulan Al-Ma'unah dari kem tentera Gerik, Perak yang kemudiannya diberkas di Bukit Jenalek, Sauk, Perak (pada 2-6 Julai 2000) yang dengan mudah juga boleh dimanipulasi oleh media untuk maksud terorisme.

\section{Komitmen Media \& Kerajaan Memerangi Islamofobia}

Stesen-stesen televisyen FTA di Malaysia telah berusaha untuk meningkatkan pengetahuan tentang kesucian Islam dan Muslim dalam kalangan masyarakat Malaysia. Menurut informan, rancangan sebegitu boleh dibahagikan kepada dua bentuk iaitu rancangan yang diterbitkan khas dengan tujuan mendidik nilai-nilai Islam dan keduanya, rancangan umum yang sebahagian besarnya berteraskan hiburan tetapi menyelitkan unsur-unsur Islam. Contohnya rancangan terbitan khas adalah Surah Pilihan, Ijazul Quran, Forum Perdana Ehwal Islam (melibatkan penggunaan media sosial facebook untuk penonton memberikan pandangan dan mengajukan persoalan-persoalan kepada ahli panel) dan siaran-siaran Azan (Subuh, Zuhur, Asar, Maghrib, Isyak) mengikut masanya dalam TV1, rancangan realiti televisyen Imam Muda (Young Imam) dalam Astro Oasis, rancangan Jejak Rasul siaran TV3 yang kini telah memasuki edisi ke-17 pada tahun 2011 memberi peluang rakyat Malaysia melihat pengaruh Islam dalam kehidupan masyarakat di serata dunia.

Rancangan-rancangan yang tergolong dalam kategori kedua adalah seperti Wanita Hari Ini, Dapur Nyonya, dan drama-drama bersiri Melayu. Rancangan Sudut Pandang siaran Astro Awani yang bukan sahaja menjemput tokoh-tokoh dan pakar-pakar dalam bidang berkaitan untuk mengupas isu-isu semasa tetapi turut menggunakan media sosial facebook (U-wartawan) untuk khalayak memberi respons terhadap program mereka. Semua ini harus dilihat menyumbang kepada peningkatan kefahaman tentang Islam dan Muslim. 
Menyentuh dari aspek pemberitaan, program-program berita berjadual di TV1 (Berita Nasional, \& Berita Wilayah), TV2 (Berita Mandarin, Berita Inggeris, Berita Tamil), TV3 (Buletin Pagi, Buletin 130, Buletin Utama, \& Nightline), NTV7 (Edisi 7 \& 7 Edition), 8TV (8TV Mandarin), dan TV9 (Berita TV9) yang terikat dengan obligasi menggalakkan (mendukung/ memupuk) matlamat dasar dan polisi kerajaan yang mengkehendakkan media membantu mempromosikan nilai-nilai Islam sesuai (mengambilkira komposisi etnik) dengan konteks masyarakat majmuk pluralistik Malaysia. Begitu juga dengan program-program ehwal semasa seperti Selamat Pagi Malaysia, Hujung Minggu Malaysia, Di Luar Lingkungan, Wadah (Suara Siswa), Khabar Malaysia, Dialog, Forum Perdana Ehwal Islam, Galeri Nasional, Isu, Apa Kata Wanita, Titik Sentuhan Terus Bertindak dan Eksklusif oleh TV1 bersama-sama Malaysia Hari Ini, Wanita Hari Ini, Aduan Rakyat, Bersamamu, 999, AlKulliyyah, Majalah3, Nona, dan Jom Ronda oleh TV3. Pihak pengurusan Astro turut mengimbangi perspektif-perspektif berita Barat dengan menyediakan saluran berita nasional seperti Astro Awani dan saluran-saluran TV pendidikan yang mendidik agama Islam khususnya Astro Oasis, Astro Ria, dan sebagainya. Terbaharu adalah TV Al-Hijrah oleh Alhijrah Media Corporation. Komitmen daripada kerajaan turut tidak terkecuali melalui pengenalan saluran berita Bernama TV.

Peranan pemberitaan juga boleh dilihat pada liputan serangan Amerika Syarikat (AS) dan Britain ke atas Iraq dari sudut berita yang berbeza. Dalam mengimbangi propaganda laporan media Barat untuk 'memutihkan' atau 'menghalalkan' serangan mereka ke atas Iraq misalannya, media di Malaysia menulis semula sudut berita yang dilaporkan mengikut ideologi dan pendirian negara berhubung isu tersebut. Terbaharu media di Malaysia turut memberi liputan meluas kepada perbicaraan simbolik terhadap George W. Bush (bekas Presiden Amerika Syarikat 2001-2009) dan Tony Blair (bekas Perdana Menteri Britain 19972007) di Kuala Lumpur atas pertuduhan (sebagai penjenayah perang/ petualang sebenar) melakukan jenayah mencabul keamanan dan melanggar undang-undang antarabangsa dalam serangan ke atas Iraq. Serangan yang diketuai Amerika Syarikat dan Britain dengan alasan Iraq memiliki senjata pemusnah massa sehingga hari ini belum dijumpai meskipun bekas Presiden Iraq, Saddam Hussein telah dijatuhi hukuman mati oleh tribunal (oleh Tribunal Tinggi Iraq pada 6hb November 2006) boneka Amerika Syarikat. Isu-isu antarabangsa seperti ini sering mendapat perhatian media di Malaysia terutamanya penindasan rejim Israel terhadap Palestin, kebangkitan negara-negara Liga Arab, dan sebagainya di mana pemberitaan di Malaysia memberikan sudut perspektif Malaysia. Contoh isu-isu yang boleh dirumuskan hasil temubual dengan informan termasuklah peristiwa Gerakan Aceh Merdeka (GAM) di Indonesia; konflik di Selatan Thai, gerakan puak Uighur, Urumuqi, Xinjiang, China menuntut kemerdekaan; Muammar Gaddafi di Libya; liputan perang di Bosnia, Iraq dan sebagainya.

Isu-isu antarabangsa yang mendapat perhatian media Malaysia ini, pada pandangan informan, - diharapkan boleh dijadikan teladan dan pengajaran kepada rakyat Malaysia. Sepertimana kata salah seorang informan, "kita tidak mahu Malaysia menjadi lokasi militanmilitan." Namun, semua isu ini memerlukan kajian yang teliti sebelum dilaporkan. Sebagai misalannya, tindakan kerajaan China mengelak orang ramai berkumpul di sesuatu tempat sewaktu darurat susulan pengeboman-pegeboman di tempat awam oleh puak pemisah (separatist) Uighur sebagai genosid terhadap orang-orang Han, mudah disalah interpretasikan sebagai tiada kebebasan agama jika mengambil tindakan pemerintahan tentera sementara yang tidak membenarkan Muslim mengerjakan solat Jumaat pada minggu tersebut. Jika pemberita mengambil inisiatif melihat peristiwa-peristiwa hitam yang berlaku beberapa hari 
sebelum itu dan sejarah Urumuqi, maka pemberita akan mendapat gambaran yang lebih tepat berkenaan apa sebenarnya yang berlaku.

Akhbar-akhbar Bahasa Melayu dan Bahasa Inggeris di Malaysia juga sering kali dilihat membantu menyiarkan waktu-waktu berbuka puasa dan bersahur mengikut zon-zon kawasan juga merupakan sumbangan atas keperihatinan akhbar-akhbar terhadap masyarakat yang beragama Islam. Kolum-kolum dalam sesetegah akhbar seperti kolum Delights yang mempersembahkan resipi makanan Melayu sebenarnya secara tidak langsung boleh membantu (secara tidak langsung) memperkenalkan budaya Muslim kepada masyarakat lain. Sungguhpun kita harus faham perbezaan antara Islam sebagai satu cara hidup atau Ad-Din dan adat resam adalah berbeza, dalam konteks Malaysia yang mana masyarakat Melayu begitu sinonim dengan Islam, maka memperkenalkan adat resam Melayu boleh dilihat sebagai antara usaha untuk memperkenalkan Islam selagi ia tidak bercanggah dengan prinsip Islam itu sendiri.

Selain itu, ada juga informan yang melihat pembingkaian sesebuah akhbar tentang isu berkaitan Muslim seperti terorisme perlu dilakukan dengan teliti: "akhbar yang berprestij adalah akhbar yang melapor dengan teliti dan berhati-hati." Berkaitan langsung dengan petikan ini, informan berpendapat bahawa pihak media tidak seharusnya mengambil kesempatan ke atas isu ini untuk menwujudkan provokasi sesama rakyat yang berlainan agama meskipun setiap akhbar ada mempunyai golongan sasaran pembaca masing-masing seperti Sin Chew Daily, Berita Harian dan New Sabah Times. Malahan, dalam hal ini juga, informan berpendapat bahawa apa yang telah dilakukan oleh sesetengah media adalah untuk menjelaskan polemik di sebalik pertikaian tersebut dan mengajak rakyat bertoleransi dalam hal ini. Keterlibatan sesetengah pihak yang tidak bertanggungjawab yang didalangi kepentingan politik terutamanya melihat majoriti penduduk Sabah dan Sarawak adalah beragama Kristian menggunakan media sosial untuk memperbesar-besarkan isu pertikaian penggunaan kalimah Allah telah menimbulkan keadaan panik seketika kepada seluruh rakyat Malaysia terutama sepanjang waktu kempen Pilihan Raya Kecil (PRK) P.212 Sibu, Sarawak (27hb Mei 2010).

Saluran radio Suria FM Sabah ketika dimulakan oleh DJ Othoe dan kini KKFM dilihat telah memecahkan tradisi radio-radio ortodoks yang begitu terikat dengan kejituan dan ketepatan penggunaan bahasa dengan menampilkan cara baharu dengan mencerminkan identiti penduduk Sabah yang tiada jurang di antara mereka. Dalam sesuatu segmen radionya akan diputarkan lagu-lagu Melayu, Inggeris, Tamil dan bahasa tempatan Sabah dan ini merupakan suatu kelainan yang dilihat mampu memecahkan tembok jurang antara kaum. Selain itu, topik-topik yang dibincangkan turut memfokus kepada isu-isu semasa sosial masyarakat Sabah. Peranan radio-radio RTM pula, termasuk saluran Bahasa Mandarin Sabah $V F M$ menyiarkan slot HIDAYAH (思想泉源) yang sudah pastinya memainkan peranan penting memberi serba-sedikit pendedahan kepada masyarakat Cina bahawasanya ajaran Islam itu menekankan kebaikan (tidak seperti sterotaip yang diwujudkan media Barat). Begitu juga dengan peranan siaran slot LAGU PATRIOTIK (爱国歌曲) yang tidak kurang pentingnya untuk menanam semangat patriotisme dalam kalangan rakyat Malaysia yang berbilang etnik. Usaha-usaha ini semuanya dipercayai berupaya membawa kepada integrasi di antara kaum. Memetik kata-kata salah seorang informan, "RTM adalah stesen penyiaran perkhidmatan awam yang bukan bermotifkan keuntungan tetapi mempunyai peranan asas untuk menjelaskan dasar-dasar kerajaan kepada rakyat." 
Walaupun ada yang melihat hal ini sebagai satu bentuk kawalan dari perspektif politik ekonomi, media di Malaysia umumnya boleh dilihat berusaha meleraikan sebarang ketegangan yang berpunca daripada hal-hal agama dan hubungan etnik. Kesemua informan sependapat bahawa pelaporan-pelaporan yang konsisten bermotifkan meleraikan sebarang konflik dalam masyarakat Malaysia yang secara sendirinya sudah merupakan pendekatan paling efektif untuk membantu menangkis sebarang persepsi negatif terhadap Islam mahupun Muslim. Dalam masa sama, media di Malaysia sentiasa peka bahawa mereka diadili oleh rakyat sepanjang masa. Ini mengingatkan mereka agar lebih berwaspada dan peka terhadap kandungan mereka.

Begitupun, terdapat juga beberapa insiden kontroversi yang telah diberikan sebagai contoh oleh informan yang menjurus kepada persengketaan antara kaum dan penganut berlainan agama seperti penyiaran karikatur jenaka menghina Nabi Mumammad Rasulullah sebagai penganas (terrorist) yang diambil daripada sebuah akhbar Denmark, Jyllands Posten oleh akhbar Sarawak Tribune pada 4hb Februari 2006. Isu-isu lain yang dibangkitkan ialah isu penempatan semula tapak pembinaan patung Mazu di Kudat, kecuaian akhbar The Star tersilap menyiarkan juadah masakan tidak halal (gambar hidangan daging babi) di dalam akhbar sisipannya yang bertajuk 'Ramadan Delights' dalam bulan Ramadan (11hb Ogos 2011), serta jenaka dan komedi yang mengandungi unsur-unsur perkauman terselit dalam iklan Ramadan (Ogos 2011) yang disiarkan oleh 8TV mengundang pelbagai reaksi daripada khalayak dan memaksa pihak 8TV memohon maaf dan menarik balik iklan tersebut. Kesemua ini merupakan contoh insiden-insiden yang menimbulkan ketidakselesaan dalam kalangan rakyat yang menyebabkan campur tangan daripada Kementerian Dalam Negeri (KDN). Dalam usaha menyatupadukan rakyat, semua isu-isu media tersebut berisiko tinggi memecahbelahkan masyarakat Malaysia.

Selain itu, komitmen daripada kerajaan Malaysia secara tidak langsung turut menyumbang kepada usaha memerangi Islamofobia. Misalannya, media di Malaysia turut didasari oleh falsafah negara yang merangkumi Rukun Negara, dan perundangan komunikasi yang sedia ada. Paling utama adalah intipati yang termaktub dalam Perlembagaan Persekutuan Malaysia misalannya berkaitan Islam sebagai agama rasmi, Bahasa Melayu sebagai bahasa kebangsaan, dan sebagainya. Agensi-agensi kerajaan berkaitan, khususnya Kementerian Dalam Negeri (KDN) mempunyai peraturan yang lebih spesifik dalam menangani hal ini seperti penerbitan semula mana-mana bahagian teks dalam Al-Quran yang memerlukan permit dan tidak boleh dicetak secara tidak terkawal. Pengusaha industri media massa di Malaysia juga turut terikat dengan garis panduan penyiaran daripada JAKIM misalannya pelakon yang bukan Islam tidak boleh memegang watak sebagai seorang Islam, tidak boleh melakonkan ibadah dengan cara salah sama ada dengan niat atau tidak untuk mempersendakan ibadah-ibadah tersebut, dan mengelakkan kandungan media yang mengandungi unsur-unsur yang bercanggah dengan akhlak.

Selaras dengan dasar kerajaan, media di Malaysia turut menolak sebarang diskriminasi terhadap wanita selari dengan Malaysia sebagai sebuah negara demokrasi. Akhbar di Malaysia juga mempunyai ruangan yang lebih banyak untuk mengupas sebarang penindasan mahupun kezaliman ke atas wanita. Begitupun, mengupas tentang hal ini, salah seorang informan informan daripada stesen televisyen berpendapat, "ruangan dalam berita televisyen masih lagi terbatas kecuali rancangan forum dan diskusi seperti Sudut Pandang." Tidak lupa komitmen kerjasama Malaysia dengan negara-negara serantau seperti Persatuan Negaranegara Asia Tenggara (ASEAN) dan dengan AS memerangi terorisme, peranan Malaysia 
dalam Pertubuhan Persidangan Islam (OIC), serta Pertubuhan Bangsa-bangsa Bersatu (PBB) yang turut mempengaruhi wacana media di Malaysia.

Berkaitan ini, penapisan kendiri (self-censorship) oleh media sendiri juga memainkan peranan sangat penting. Sebagai misalannya mengikut salah seorang informan, "Apabila menyentuh soal etnik dan agama seperti dengan tidak memperbesarkan insiden-insiden bakar gereja, buang kepala babi hutan ke dalam masjid, mahupun gantung kepala lembu di pintu pagar kuil kerana itu semuanya adalah perbuatan sabotaj segelintir kecil parasit-parasit dalam masyarakat Malaysia yang devian, berfikiran cetek dan ada yang buat itu kerana sukasuka." Media, katanya lagi, dalam hal ini akan cuba menekankan kesalahan-kesalahan tersebut sebagai tingkahlaku tidak rasional berbanding menyalakan api persengketaan sesama kaum. Pendapat daripada seorang informan lain, "Usaha-usaha untuk menjejaskan kestabilan negara oleh pihak-pihak yang tidak bertanggungjawab merupakan masalah paling serius dihadapi negara pasa masa kini di mana rakyat tertakluk kepada perhimpunan protes yang sering kali menjadi rusuhan yang menyebabkan ketidakstabilan negara." Ini adakalanya dipengaruhi oleh faktor latar belakang pengamal media. Sebagai misalannya seorang informan yang merupakan ketua editor di salah sebuah bilik berita hal ehwal semasa sebuah stesen televisyen menyatakan, "sesebuah keluarga di Sabah dan Sarawak boleh lihat .... the siblings, menganut pelbagai agama. Thus, degree of tolerances higher. Furthermore, the jurang between ethnics in Sabah Sarawak doesn't looks like Malay, Chinese and Indian in Peninsular Malaysia." Beliau menjelaskan ciri-ciri sesebuah keluarga di Sabah dan Sarawak seperti adik beradik yang memegang agama yang berbeza secara tidak langsung mempengaruhi tahap toleransi di antara individu yang mempunyai kepercayaan agama berlainan apatah lagi jurang antara etnik Melayu, Cina dan India di Sabah berbeza dengan di Semenanjung Malaysia. Latar belakang editor juga mempengaruhi keputusannya dalam proses penghasilan berita. Apabila seseorang editor mempunyai latar belakang kekeluargaan asalnya sama etnik tetapi berubah agama disebabkan perkahwinan dengan etnik-entik lain mahupun pegangan agama berlainan, ia secara tidak langsung juga akan mempengaruhi penapisan kendiri daripada diri beliau terhadap isu-isu perkauman dan agama.

Namun, selain faktor itu, kerelevanan sesuatu isu tersebut kepada khalayak sasaran mereka juga mempengaruhi keputusan dalam kalangan pengampang media. Sebagai misalannya menurut salah seorang informan, media di Sabah dan Sarawak turut menerima surat daripada pihak berkuasa $(\mathrm{KDN})$ meminta bantu meredahkan konflik pertikaian penggunaan kalimah Allah (2010) yang disusuli dengan siri serangan ke atas gereja, masjid dan kuil, mereka tidak respons kepada pemintaan tersebut kerana hal tersebut tidak relevan kepada konteks Sabah dan Sarawak. Ini berdasarkan petikan informan, "but media in Sabah and Sarawak ignore the request [of publishing such stories because] as it isn't relevant to [to the context] Sabah Sarawak context ......... [the editor as a gatekeeper] doesn't feel necessary to perbesar-besarkan the isu [exaggerate the isse] in here." Tambah editor tersebut lagi, isuisu seperti ini sampai kepada pengetahuan masyarakat di Sabah dan Sarawak menerusi media dari Semenanjung Malaysia dan respons daripada media tempatan di Sabah dan Sarawak hanyalah pada bahagian-bahagian penyelesaiannya kepada masalah tersebut.

\section{Isu-Isu Dan Cabaran}

Cabaran semasa media di Malaysia hari ini ialah terpaksa bersaing dengan saluran-saluran media dari luar negara dalam era globalisasi. Menurut salah seorang informan, "media di Malaysia sebenarnya hanyalah secebis kecil daripada keseluruhan saluran-saluran media yang ada dalam 'dulang' [besar] yang boleh diakses oleh rakyat Malaysia dan ini belum mengambilkira media sosial lagi." Konsumer stesen siaran berbayar Astro misalannya 
mempunyai pelbagai saluran berita 24 jam sehari dan tujuh hari seminggu yang boleh dipilih. Mereka mempunyai BBC World News, CNN International News, Al-Jazeera English (AJE), CNBC Asia, CCTV4, CCTV9 dan sebagainya. Begitupun dengan kepesatan teknologi media memasuki era baru dengan kemunculan televisyen protokal internet (IPTV - Internet protocol television), sesiapa sahaja yang mempunyai akses kepada Internet boleh mengikuti saluran berita antarabangsa secara online. Antara saluran televisyen yang disediakan oleh IPTV tersebut adalah BBC Knowledge, BBC Lifestyle, CBeebies, Channel News Asia, DWTV Asia, Channel V Taiwan, Euronews, dan Star Chinese Channel. Contoh berita berkenaan insiden pengeboman di Bali, genosid di Selatan Thailand, pengeboman di India, pengeboman oleh puak Ugur ke atas kawasan-kawasan orang-orang Han di Urumuqi, Xinjiang, China dan sebagainya semuanya boleh diakses melalui saluran-saluran media asing tersebut. Walaupun fenomena ini ada kebaikannya, ia juga menyumbang ke arah prejudis dan sterotaip negatif yang membawa kepada fenomena Islamofobia menular dalam kalangan masyarakat Malaysia.

Ini belum mengambilkira saluran-saluran hiburan seperti $H B O, M A X$ (Cinemax), STAR Movies dan sebagainya besar pengisian kandungannya terdiri daripada filem-filem Hollywood yang mengalihkan perhatian daripada (mensasarkan) komunisme kepada Islam dan Muslim yang disamakan dengan terorisme sebagai watak jahat dalam filem-filem mereka. Ini adalah contoh maklumat-maklumat yang terpesong disebabkan salah tafsir terhadap konsep-konsep Islam seperti Jihad, ataupun mungkin sahaja ada yang sengaja diputarbelitkan kebenaran. Sepertimana menurut informan, "jalan cerita dan interpretasi penerbit berita yang dipengaruhi oleh ideologi dan kepentingan nasional masing-masing akan mencorak interpretasi mereka terhadap insiden-insiden tersebut yang seterusnya disampaikan dalam berita yang mereka terbitkan." Ini dengan mudahnya memberi satu versi cerita yang berkecenderungan memburukkan dan mengaibkan nama Islam dan Muslim. Cabaran utama masa akan datang adalah probabiliti masyarakat Malaysia mengakses kepada saluran-saluran yang tidak ditapis walhal ketika ini semua pihak bergelut berusaha menapis penularan Islamofobia. Berkaitan ini, kemunculan Televisyen Protokal Internet (IPTV) mulai tahun 2010 yang mana audien mengakses saluran televisyen melalui komputer dan telefon bimbit dijangkakan akan merubah wajah mediaskap Malaysia sekali lagi selepas pengenalan televisyen satelit ASTRO pada tahun 1996.

Perkembangan ini secara tidak langsung mempunyai impak kepada masyarakat Malaysia yang terdiri daripada pelbagai etnik dan mengamalkan pelbagai kepercayaan agama, yang dilihat secara sendirinya membuka ruang kepada perselisihan pendapat dalam kalangan masyarakat majmuk. Percanggahan pendapat bukan sahaja boleh disaksikan berlaku disebabkan faktor demografi masyarakat pluralistik Malaysia tetapi percanggahan pendapat antara golongan yang berpegang kuat kepada nilai-nilai agama dengan yang golongan yang lebih liberal pemikiran mereka dipengaruhi oleh nilai-nilai modenisasi. Golongan liberal dilihat wujud hasil daripada kepincangan dewasa ini kesan daripada penularan nilai-nilai Barat yang meresap ke dalam pemikiran generasi baharu di Malaysia. Fahaman yang timbul atas dasar hak asasi manusia tetapi merosakkan akidah seperti tuntutan hak asasi manusia golongan lesbian, gay, biseksual dan transgender (LGBT) bawah Seksualiti Merdeka atas prinsip demokrasi dan kebebasan bersuara ditentang hebat golongan yang dilihat konservatif. Begitu juga dengan aktiviti-aktiviti politik yang berselindung di sebalik agama melalui contoh propaganda-propaganda undi $\mathrm{BN}$ akan masuk neraka yang secara umumnya mengelirukan ramai masyarakat. Soal-soal kecelaruan sosial (social disorder) ini amat mudah menimbulkan salah faham dalam kalangan rakyat Malaysia. 
Sebagaimana menurut pendapat seorang lagi informan, "Islamofobia tidak mungkin dapat diselesaikan oleh sebuah negara sahaja, .... Malaysia sendiri tidak boleh menangani penularan fenomena ini, ia memerlukan komitmen dan ketelusan daripada semua negara [yang terlibat]." Hujah lanjut beliau, "Persefahaman harus dicapai di antara semua negara dan ini hampir mustahil akan berlaku dalam konteks masa kini." Bukan sahaja media di Malaysia harus mennghormati kepentingan publik hak semua rakyat Malaysia tanpa mengira etnik, agama, dan budaya, tetapi media harus berfikir dalam konteks yang lebih global. Media di Malaysia bukan sahaja harus memainkan peranan penting menyelesaikan pertikaian fahaman agama dan ideologi, menyeru bertolak-ansur, dan merungkai konflik, dan bukannya sebagai batu api yang menyemarakkan lagi persengketaan untuk konteks dalaman negara tetapi suatu konteks yang lebih luas.

Namun begitu, pihak RTM turut menghadapi tekanan daripada segelintir rakyat yang tidak memahami peranan dan tanggungjawab yang diamanahkan kepada mereka. Keadaan ini dikeruhkan lagi dengan kritikan-kritikan daripada pihak-pihak tertentu yang bermotifkan kepentingan politik masing-masing. Kritikan ini merangkumi pertikaian sebab populariti RTM tidak setanding stesen-stesen penyiaran lain yang di bawah Media Prima walhal RTM merupakan stesen penyiaran tertua di Malaysia. Walau bagaimanapun, sepertimana menurut informan, faktor utama menyebabkan RTM dikecam adalah kerana RTM beroperasi dengan bajet daripada kerajaan dan bukan seperti stesen-stesen swasta yang mengutamakan hiburan dan keuntungan. Jika dilihat dengan lebih teliti, tiada kandungan siaran RTM yang salah, mahupun tidak ikut trend semasa, tetapi penekanannya pada pendidikan dan tanggungjawab sosial mengikut garis panduan yang dikeluarkan oleh kerajaan menyebabkan pengisian kandungan saluran-saluran RTM sedemikian rupa. Sungguhpun hal ini dikritik oleh sesetengah pengamal dan pengkaji media, dari satu sudut, RTM boleh dilihat sebagai sebuah organisasi media yang tidak semata-mata mengharapkan keuntungan dengan menyiarkan rancangan hiburan. RTM boleh berubah sepertimana penyiaran komersil stesen-stesen swasta lain tetapi siapakah yang harus dipertanggungjawabkan untuk menjaga nilai dan budaya masyarakat Malaysia. Apatah lagi ini antara kesepakatan utama yang termaktub dalam Wawasan 2020 yang berhasrat melahirkan masyarakat Malaysia yang sempurna dengan nilai moral dan etika yang tinggi. Justeru itu, persepsi negatif terhadap kredibiliti RTM ini perlu dikikis kerana tanggungjawab sosial terhadap rakyat yang utama kini dipikul RTM. Dalam hal ini, pastinya salah satu agenda penting itu termasuklah usaha mengurangkan Islamofobia dalam kalangan masyarakat Malaysia itu sendiri.

\section{Kesimpulan}

Apa yang dibincangkan di dalam kertas kerja ini memfokus kepada wacana media di Malaysia dan fenomena Islamofobia. Fenomena yang disebabkan oleh prejudis terhadap agama Islam dan kepada golongan Muslim itu telah mendapat perhatian daripada pengeluar kandungan media di Malaysia khususnya untuk menangkis persepsi-persepsi negatif yang dilontarkan dan seterusnya berusaha untuk mengimbanginya dengan maklumat-maklumat yang tepat dan benar. Malaysia turut terkena tempias daripada propanganda oleh media Barat dengan alasan memerangi terorisme dan melihat senario ini sebagai suatu ancaman kepada keselamatan dan kestabilan dalaman negara. Namun, kehebatan media Barat yang mempunyai akses ke seluruh dunia berikutan teknologi-teknologi komunikasi yang lebih canggih daripada kebanyakan negara-negara Islam yang masih bergelar Negara-negara Membangun adakalanya begitu sukar dihalang. Kerajaan boleh menghalang produksi media berkenaan daripada memasuki negara tetapi kerajaan masih tidak mampu menghalang mana-mana individu perseorangan akses terhadapnya dalam internet. Maka, tindak-tanduk kuasa-kuasa Barat tersebut sedikitsebanyak telah menimbulkan kegusaran kepada negara-negara seperti Malaysia sendiri 
terutamanya bimbang akan menimbulkan perselisihan sesama masyarakat multi-etnik Malaysia. Hal ini seterusnya mendesak saluran-saluran domestik media memainkan peranan penting untuk memperbetulkan persepsi-persepsi negatif yang dilontarkan dan seterusnya menyedarkan (enlighten) rakyat tentang ajaran Islam yang sebenarnya.

Maka, polemik anti-Islam yang disebabkan perbezaan ideologi di antara Islam dengan Barat telah menular ke seluruh dunia. Penularan Islamofobia telah muncul menjadi cabaran baharu kepada media nasional untuk menangkis pandangan serong terhadap Islam dan Muslim. Maka hari ini, kandungan media Malaysia mengabungkan kepelbagaian maklumat dan perspektif, hiburan, pendidikan dan pembujukan untuk mengurangkan impak Islamofobia. Komitmen dan usaha-usaha daripada media di Malaysia setakat ini harus diberikan kredit kerana sentiasa peka dengan isu-isu sensitif agama dan bahasa, prejudis budaya dan perkauman. Begitupun media di Malaysia masih perlu berhati-hati dengan dakyah-dakyah politik dalaman negara yang cenderung memanipulasikan isu-isu perkauman dan agama sebagai modal berkempen untuk meraih undi. Implikasinya pihak yang tidak bertanggungjawab akan mewujudkan skeptikal terhadap Islam mahupun Muslim sudah pastinya akan menanam kebencian agama dan etnik lain dalam kalangan rakyat Malaysia.

\section{Rujukan}

Abdul Jalil Sajid. 2005. "Islamophobia: A new word for an old fear." dalam Seminar "Osce Conference on Anti-Semitism and on Other Forms of Intolerance" di Cordoba, 8 \& 9 June 2005. Diambil dari http://www.osce.org/documents/cio/2005/06/15198_en.pdf. We retrieved the paper pada $26 \mathrm{hb}$ November 2011.

Agence France-Presse. 3/8/2011. Malaysian TV removes Ramadan ads amid 'racism' complaint. diambil dari http://news.malaysia.msn.com/regional/article.aspx?cpdocumentid=5116819 pada 3hb Ogos 2011.

Merican, Ahmad Murad (2005). 'Religious Ideas: Islam in the Malay Press,' in Syed Farid Alatas, ed. Covering Islam: Challenges and Opportunities for Media in the Global Village. Singapore: Centre for Research on Islamic and Malay Affairs and Konrad Adenauer Foundation.

Ahmad Murad Merican. 2010. Orientalism in reporting religion: Approaches to teaching journalism and Islam as a civilization. Asia Pacific Media Educator, 20, 163-176.

Allen, C. 2010. An Overview of Key Islamophobia Research. The National Association of Muslim Police (NAMP).

Anwar Shaheen. 2009. Patriarchal Education and Print Journalism: Their Emancipating Impact on Muslim Women of India during 1869-1908. Pakistan Journal of History and Culture XXX(2): 1-42.

Archer, B. 2007. Family Law Reform and the Feminist Debate: Actually-Exixting Islamic Feminism in the Maghreb and Malaysia. Journal of International Women's Studies. 8(4): 49-59.

Afshar, H. 2008. Can I See Your Hair? Choice, Agency and Attitudes: The Dilemma of Faith and Feminism for Muslim Women Who Cover. Ethic and Racial Studies. 31(2): 411427.

Boyle, M.P., Schmierbach, M., Armstrong, C.L., Cho, J., McCluskey, M., McLeod, D.M., Shah, D.v. 2006. Expressive Responses to News Stories about Extremist Groups: A Framing Experiment. Journal of Communication 56: 271-288.

Brown, G. 2005. The rough and rosy road: Sites of contestation in Malaysia's shackled media industry. Pacific Affairs 78: 39-56. 
Chandra Muzaffar. 2004. "The Media, Islam and the West" dalam Eashwar, S.S. (ed.) 2004. Dialogue, Understanding and Tolerance. Asia Media Summit 2004. Asia-Pacific Institute for Broadcasting Development. m/s. 22-32.

Chomsky, N. 2003. Power and Terror: Post-9/11 Talks and Interview. New York: Seven Stories Press.

Cottle, S. 2000. Ethnic Minorities and the Media: Changing Cultural Boundaries. Buckingham: Open University of Press.

Dixon, T.L., \& Linz, D. 2000. Race and Misrepresentation of Victimization on Local Television News. Communication Research 27: 547-573.

Eashwar, S.S. (editor). 2004. Dialogue, Understanding and Tolerance. First Asia Media Summit 2004. Asia-Pacific Institute for Broadcasting Development.

Elliott, C.W., \& Greer, C.F. 2010. Newsworthiness and Islam: An Analysis of Values in the Muslim Online Press. Communication Quarterly 58(4): 414-430.

Entman, R.M. 1990. Modern Racism and the Image of Blacks in Local Television News. Critical Studies in Mass Communication 7: 332-345.

Entman, R.M. 1992. Black in the News: Television, Modern Racism, and Cultural Changes. Journalism Quarterly 69:341-361.

Ernst, Carl W. (2004). Rethinking Islam in the Contemporary World. Edinburgh: Edinburgh University Press.

Esposito, J.L. 1992. The Islamic Threat: Myth or Reality. Oxford: Oxford University Press.

Fahmy, S. 2010. Contrasting Visual Frames of our Times: A Framing Analysis of English and Arabic-language Press Coverage of War and Terrorism. Gazette 72(8): 695-717.

Forrest, J. \& Dunn, K. 2006. Racism and Intolerance in Eastern Australia: a geographic perspectives. Australia Geographer 37(2): 167-186.

Foster, N., Cook, K., Barter-Godfrey, S., \& Furneaux, S. 2011. Fractured Multiculturalism: Conflicting Representations of Arab and Muslim Australian in Australian Print Media. Media, Culture \& Society 33(4): 619-629.

Gans, H. 1979. Deciding What's News: A Study of CBS Evening News, NBC Nightly News, Newsweek, and Time. New York: Pantheon.

Gerbner, G., Gross, L., Morgan, M., Signorielli, N., \& Shanahan, J. 2002. Growing up with television: Cultivation Process. Dlm. Bryant, J. \& Zillmann, D. (Eds.). Media Effects: Advances in Theory and Research $\left(2^{\text {nd }}\right)$. Mahwah, NJ: Erlbaum. m/s. 43-68.

Gorham, B.W. 2006. News Media's Relationship With Stereotyping: The Linguistic Intergroup Bias in Response to Crime News. Journal of Communication 56: 289-308.

Hall, S. 1992. 'New Ethnicities in Race'. Dalam Rattansi, A. \& Donald, J. 1992. Culture and Difference. London: Sage.

Humphreys, R.S. 1992. Islamic History: A Framework for Inquiry. Cairo: The American University in Cairo Press.

Ilhem, A., \& Abeer, N. 2011. Framing Political Islam in Popular Egyptian Cinema. Middle East Journal of Culture and Communication 4(2): 203-224.

Kamali, M.H. 2000. Freedom of Expression in Islam. Kuala Lumpur: Ilmiah Publisher.

Kamali, M.H. 2002. Freedom, Equality and Justice in Islam. Kuala Lumpur: Ilmiah Publisher.

Khiabany, G. 2003. Dr-Westernizing Media Theory, or Reverse Orientalism: 'Islamic Communication' as Theorized by Hamid Mowlana. Media, Culture \& Society 25: 415422.

Kovach, B. \& Rosenstiel, T. 2001. The Elements of Journalism: What Newspeople Should Know and the Public Should Expect. New York: Three Rivers Press.

Lowe, B. 1985. "Islam and the media In New South Walesee, Anti-Discrimination Board (ed.), Islam in Australia, Sydney: New South Wales Anti-Discrimination Board. 
Mahony, I. 2010. Diverging Frames: A Comparisons of Indonesian and Australian Press Portrayals of Terrorism and Islamic Groups in Indonesia. Gazette 72(8): 739-758.

Manning, P. 2006. Australians Imagining Islam. Dalam 'Poole, E. \& Richardson, J.E. (Ed.). Muslims and the Media. London: IB Tauris. m/s. 128-141.

Marx, T., 2008. "Islam and Media Discourses in India: Constructing Islamophobia". International Journal of South Asian Studies, 1(2), 284-83.

Meena Sharify-Funk. 2009. Representing Canadian Muslims: Media, Muslim Advocacy Organizations, and Gender in the Ontario Shari'ah Debate. Global Media Journal :7389.

Norris, P., Kern, M. \& Just, M. (ed.). 2003. Framing Terrorism: The News Media, the Government and the Public. New York: Routledge.

Pludowski, T. (ed.) 2007. How the World's News Media Reacted to 9/11: Essays from Around the Globe. Spokane, Washington: Marquette Books.

Poynting, S. \& Manson, V. 2006. 'Tolerance, Freedom, Justice and Peace'? Britain, Australia and Anti-Muslim Racism Since 11 September 2001. Journal of Intercultural Studies 27(4): 365-391.

Poynting, S. \& Manson, V. 2007. The Resistible Rise of Islamophobia: Anti-Muslim racism in the UK and Australia before 11 September 2001. Journal of Sociology 43(1): 6196.

Romano, A. 2003. Politics and the Press in Indonesia: Understanding an Evolving Political Culture. London: Routledge.

Rose, G., \& Hoge, J.F. Jr. 2001. How Did this Happen: Terrorism and the New War. USA: Foreign Relation/ PublicAffairs.

Amir Saeed. 2007. Media, Racism and Islamophobia: The Representation of Islam and Muslims in the Media. Sociology Compass 1(2): 443-462.

Said, E. 1997. Covering Islam: How the Media and the Experts Determine How We See the Rest of the World. London: Vintage. Said, Edward (1981). Covering Islam: How the Media and the Experts Determine How We See the Rest of the World. New York: Pantheon (1979). Orientalism. New York: Vintage Books.

Shamsul Amri Baharuddin (2005). " "Islam Popular".' Dewan Budaya, May, p. 42-44.

Shamsul Amri Baharuddin. 2008. Many Ethnicities, Many Cultures, One Nation: The Malaysian Experience. Kertas Kajian Etnik UKM Bil. 2 (November) 2008.

Steele, J. 2011. Justice and Journalism: Islam and Journalistic Values in Indonesia and Malaysia. Journalism 12(5): 533-549.

Syed Arabi Idid. 1989. Malaysia. In Achal Mehra (ed). Press System in ASEAN States. Singapore: AMIC. m/s. 41-56.

Tuchman, G. 1978. Making News: A Study in the Construction of Reality. New York: Free Press.

Zafar Iqbal. 2010. The Constructions and Measurements of Islamophobia. Kertas kerja yang dibentangkan di Seminar "The International Conference on Communication and Media 2010" (iCome'10). Bayview Hotel, Melaka, Malaysia. 18-20 Jun 2010.

Zelizer, B. \& Allan, S. (ed.). 2002. Journalism After September 11. London: Routledge. . Barat perlu kutuk Islamofobia. Utusan Malaysia. (10 Jun 2008). m/s. 3.

www.48hourfilm.com

www.IslamOnline.net 